\title{
Brain-stem auditory evoked responses during microvascular decompression for trigeminal neuralgia: Predicting post-operative hearing loss
}

\author{
Ramachandran Ramnarayan, Ian Mackenzie \\ Departments of Neurosurgery and Neurophysiology, The Walton Center for Neurology and Neurosurgery, Liverpool, United Kingdom
}

Context: The importance of brainstem auditory evoked potential monitoring in reducing hearing loss during microvascular decompression for trigeminal neuralgia is now accepted. However the extent of the changes in the pattern of these potentials and the safe limits to which these changes are relevant in reducing postoperative hearing loss have not been established. Aims: The aim of this study is to quantify these changes and relate these to the postoperative hearing loss. Settings and Design: This study was done at the Walton Centre for neurology and neurosurgery, Liverpool, United Kingdom. The study was designed to give a measure of the change in the wave pattern following microvascular decompression and relate it to postoperative hearing loss. Materials and Methods: Seventy-five patients undergoing microvascular decompression for trigeminal neuralgia had preoperative and postoperative hearing assessments and intraoperative brainstem auditory evoked potential monitoring. Statistical Analysis Used: Chi-square tests. Results: It was found that the wave $V$ latency was increased by more than $0.9 \mathrm{~ms}$ in nine patients, eight of whom suffered significant postoperative hearing loss as demonstrated by audiometry. It was also seen that progressive decrease in amplitude of wave $\mathrm{V}$ showed progressive hearing loss with $25 \%$ loss when amplitude fell by 50 and $100 \%$ loss when wave $V$ was lost completely. However most of the patients did not have a clinically manifest hearing loss. Conclusions: A per-operative increase in the latency of wave $V$ greater than $0.9 \mathrm{~ms}$ and a fall of amplitude of wave $\mathrm{V}$ of more than $50 \%$ indicates a risk to hearing.

Key words: Hearing loss, microvascular decompression, trigeminal neuralgia, wave $\mathrm{V}$ latency

\section{Introduction}

Microvascular decompression (MVD) is a well-accepted treatment for trigeminal neuralgia (TGN). It is argued by many to be the treatment of choice, even in the elderly because of its high rate efficacy maintained in the long term. ${ }^{[1-5]}$ Attention has rightly focused on the morbidity of the procedure, acknowledged to be greater than that of other treatment modalities. In particular, hearing loss is a recognized complication of MVD, ${ }^{[3,6,7]}$ thought to be due to traction on the closely related auditory nerve. The integrity of the auditory nerve and to some extent the brainstem can be monitored peroperatively using brainstem auditory evoked potentials (BSAEP). ${ }^{[6-}$ ${ }^{11]}$ Many studies have shown the effectiveness of intraoperative BSAEP monitoring in reducing hearing loss during MVD for TGN..$^{[6-12]}$ Some of these ${ }^{[8,9,11]}$ have also shown the correlation of wave $\mathrm{V}$ latency with subsequent auditory outcome. Radtke ${ }^{[7]}$ retrospectively compared the auditory morbidity of posterior fossa microvascular decompressive surgery before and after the introduction of intraoperative brainstem auditory evoked potentials. They concluded that a significant decrease in operative morbidity was directly associated with the use of intraoperative evoked potential monitoring. Raudzens and Shetter ${ }^{[11]}$ concluded that BSAEP monitoring provided a good predictor of postoperative auditory status and may have prevented permanent neurological deficits in a small segment of patients by alerting the surgeon to potentially reversible abnormalities. Moller ${ }^{[10]}$ suggested that intraoperative BSAEP monitoring has contributed to improvement in preservation of hearing during MVD. Some authors ${ }^{[8]}$ have felt that the surgeon should only be made aware of the changes in evoked potentials that equal or exceed levels that may indicate permanent injury whereas others ${ }^{[10]}$ opine that the surgeon should be informed about changes as soon as they become larger than the small variations that are normal for such potentials. Still some 


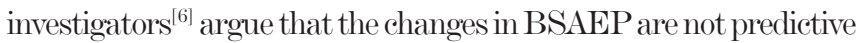
of acoustic nerve damage as postoperative hearing is preserved. In this work, like that of other ${ }^{[10-14]}$ loss of amplitude and increase in latency of wave $\mathrm{V}$ was considered to be the most important predictor of hearing impairment, but to date not much work has been done to quantify these changes and correlate it with subsequent hearing loss during MVD for TGN. In fact there is no clear consensus on the degree of latency shift and amplitude change necessary to represent a risk to later auditory function. ${ }^{[15]}$

The objective of this study was to quantify the changes in the BSAEP during microvascular decompression for trigeminal neuralgia and to relate these changes to postoperative hearing impairments.

\section{Materials and Methods}

The policy of the unit is to offer MVD to patients with neurovascular compression demonstrated preoperatively by magnetic resonance imaging. ${ }^{[4,16]}$ All patients undergoing this procedure in our unit have BSAEP monitored during the operative procedure. Seventy-five such consecutive patients undergoing MVD for TGN due to vascular compression were assessed in this study.

Preoperatively bilateral pure tone hearing thresholds across the frequency range $0.5 \mathrm{kHz}$ to $8 \mathrm{KHz}$ were established using a recently calibrated Kamplex AD40 audiometer with noise-excluding earphones. The audiometric assessments were standardized according to the American National Standards Institute. The patients were explained the tests in detail and all patients took part in the audiometry satisfactorily. Patients with severe pain or bandages had headphones applied to individual ears. BSAEP recordings were also standardized in all cases. The same investigator (IM) did all the audiograms and the brain stem evoked potentials. Nine patients out of a total of 84 who had preoperative ipsilateral hearing impairment or did not have a good audiogram were excluded from the study.

The patients were induced with using a combination of propofol, ramifentanil and atracurium and maintained with sevoflurine and air mixture and positioned in the park bench position with the ipsilateral mastoid uppermost.

Intraoperative monitoring of BSAEP was carried out using a Nicolet Spirit system (Nicolet Biomedical, Wisconsin). Three subdermal needles were placed for recording: the active electrode on the ipsilateral mastoid, reference at the vertex and earth applied to the forehead. Square wave click stimuli were applied using insert earphones at a frequency of $33.3 \mathrm{~Hz}$ and amplitude of 85 dB. Measurements were made preincision, prior to dural opening and from the time of dural opening until wound closure. The parameters analyzed for this study were the increase in latency and amplitude of wave $\mathrm{V}$. Wave $\mathrm{V}$ can be detected even at near threshold levels and is normally found at $5.6 \pm 0.23 \mathrm{~ms}^{[4]}$ Abnormal wave latency was defined as an increase in latency greater than 3 standard deviations over normal mean value (normal value $4.77 \mathrm{~ms}$ ). ${ }^{[8]}$ During surgery the surgeons are verbally told that latency is changing by having the responses stacked [Figure 1]. Any change can then be seen appreciated easily. Often there is no magic figure but a trend or even just a slight increase each time becomes really apparent as compared to previous response because up to 16 waves are visualized on the screen at any one time.

In the postoperative period all patients were asked about hearing at the bedside. None of the patients complained of any hearing loss. Pure tone audiometry was repeated (as preoperatively) 48 hours postoperatively and/or during the first follow-up visit and the average hearing threshold was tabulated. Tympanometry and otoscopy was done before the audiometry by an ENT surgeon (IM) to rule out any middle ear pathology. Only the information for the speech frequencies (1, 2 and $3 \mathrm{kHz}$ ) was used for the analysis. A change of $20 \mathrm{dBHL}$ in the hearing threshold was taken as significant. ${ }^{[7,12]}$

All patients were followed up after three months and were asked about the hearing. Some patients (eight) mentioned that the hearing was probably slightly less in the operated side but was not a problem. These patients were then further tested by clinical as well as audiometry. Clinical assessment was done was done by whispering into each ear while masking the other ear. Audiometry was also done in all these patients as previously.

Statistical analysis was done using the Chi-square tests.

\section{Results}

There were 75 patients in this study, 51 females and 24 males. The age ranged from 28 to 77 with an average of 55 years.

The patients were divided into four groups based on the hearing postoperatively as compared to preoperative hearing. It was seen that $73 \%$ of our patients had no change in the hearing on the operated side and surprisingly about $15 \%$ had some improvement in ipsilateral hearing [Table 1]. All patients (nine cases) with hearing loss had this on the ipsilateral side and all these were of sensorineural type. Interestingly, this hearing loss was not appreciated by the patients. It was seen that the clinical assessment of whispering was normal but the audiometry was definitely

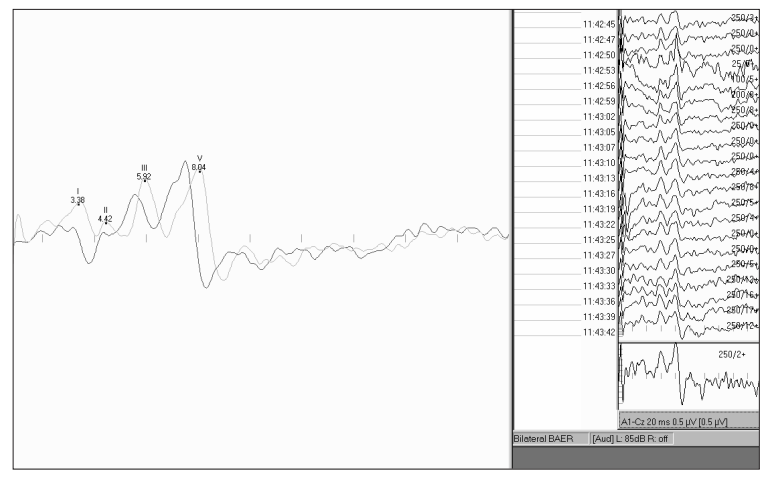

Figure 1: Wave $V$ latency of $1 \mathrm{~ms}$ with loss of wave $\mathrm{I}$. The dark green tracing shows preincision record and light green tracing shows the latency of wave $\mathrm{V}$ with stalked responses shown on the right side of figure 
Table 1: Hearing status postoperatively

\begin{tabular}{|c|c|c|c|}
\hline Hearing status & \multicolumn{2}{|c|}{ Number } & Percent \\
\hline Improved & \multicolumn{2}{|c|}{11} & 14.67 \\
\hline Same & \multicolumn{2}{|c|}{55} & 73.33 \\
\hline Decreased & \multicolumn{2}{|c|}{7} & 9.33 \\
\hline Loss & \multicolumn{2}{|c|}{2} & 2.67 \\
\hline \multicolumn{4}{|c|}{$\begin{array}{c}\text { Table 2: Wave } V \text { latency compared with hearing loss } \\
\text { (maximum increase in wave } V \text { latency recorded during } \\
\text { surgery) }\end{array}$} \\
\hline Latency increase & $<0.6 \mathrm{~ms}$ & $0.6-0.9$ & $>0.9 \mathrm{~ms}$ \\
\hline Hearing impaired & 0 & 1 & 8 \\
\hline Normal hearing & 58 & 7 & 1 \\
\hline Total & 58 & 8 & 9 \\
\hline
\end{tabular}

Chi-square value $=58.29 P<0.000$

showing a drop suggestive of hearing loss.

\section{Wave V latency and postoperative hearing}

The increase in the latency of wave $V$ was calculated as defined earlier. There was a correlation between peak latency increase and postoperative hearing deficit. It was seen that of the nine patients who had an increase in latency of wave $\mathrm{V}$ more than $0.9 \mathrm{~ms}$, hearing impairment was seen in $89 \%$ [Table 2]. In subjects with no change in hearing the average increase in the latency of wave $\mathrm{V}$ was $0.6 \mathrm{~ms}$ or less from the beginning to the end of the operation. Eight patients had an increase in the latency of wave $V$ between 0.6 and $0.9 \mathrm{~ms}$, which improved to base line by the end of the procedure. In this group only one patient had loss of hearing and she had an average wave V latency of $0.89 \mathrm{~ms}$. It can be seen that increase in the latency of wave $V$ was related to the hearing loss and this was statistically significant $(P<0.000)$. The greatest increase in latency of wave $V$ was seen when surgeons in training were operating (up to $2.17 \mathrm{~ms}$ ). We had a mean displacement of $0.92 \mathrm{~ms}$ in our series. [Figure 1] illustrates a case with wave $\mathrm{V}$ latency of about $1 \mathrm{~ms}$.

\section{Wave $V$ amplitude}

The amplitude of wave $V$ per-operatively was compared to the hearing loss. From Table 3 it is seen that when amplitude loss was 50 , about $25 \%$ of patients had hearing loss and this was progressive. But when this was $100 \%$ the hearing loss was $100 \%$. This finding also was statistically significant $(P<0.0015)$. It was observed that a break from retraction and surgery for a few minutes was usually associated with some recovery of both amplitude and latency changes. Figure 2 illustrates a case with loss of amplitude of wave $\mathrm{V}$ of about $50 \%$.

It was tried to separately analyze the correlation of hearing loss to increase in wave $V$ latency of $0.9 \mathrm{~ms}$ or more and greater than $50 \%$ decrease in amplitude of wave $\mathrm{V}$ versus those in whom only one of these parameters was affected [Table 4]. It is seen only in one case that when the amplitude was reduced by $75 \%$ did hearing loss noticed with increase in latency below $0.9 \mathrm{~ms}$. In all other cases both amplitude and increase in latency of wave $V$ seemed equally significant. However, meaningful correlation coefficients
Table 3: Amplitude loss with hearing loss

\begin{tabular}{lcc}
\hline Amplitude & No. of pts & No. of hearing impaired (\%) \\
Same & 50 & $0(0)$ \\
Reduced & & \\
$25 \%$ & 4 & $0(0)$ \\
$50 \%$ & 8 & $2(25)$ \\
$75 \%$ & 11 & $5(45)$ \\
$100 \%$ & 2 & $2(100)$ \\
\hline
\end{tabular}

Chi square value $8.748 P<0.0015$

\begin{tabular}{lccc}
\hline \multicolumn{4}{c}{ Table 4: Comparison of hearing loss with both latency and } \\
hearing loss
\end{tabular}

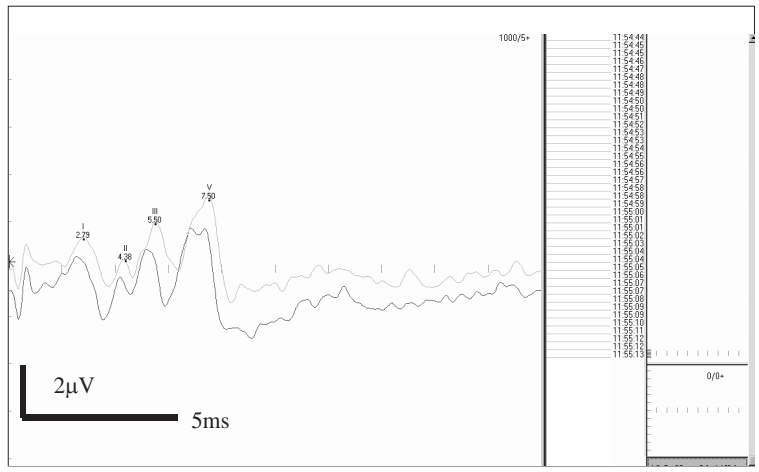

Figure 2: Loss of amplitude of wave $\mathrm{V}$ by $50 \%$. The light green tracing shows preincision record and dark green tracing shows the loss of amplitude of wave $\mathbf{V}$

could not be worked out because of insufficient sample size.

\section{Discussion}

This study deals with brainstem evoked auditory potentials during microvascular decompression for trigeminal neuralgia and the relation of BSAEP to postoperative hearing loss. Audiometry has demonstrated abnormalities postoperatively with smaller intraoperative shifts in wave $V$ latency than had previously been thought significant. It was seen that both increase in latency and decrease in amplitude of wave $V$ were indicators suggestive of postoperative hearing loss.

The importance of BSAEP monitoring in MVD has been clearly shown by many studies. ${ }^{[6-13,17]}$ The latency of peak wave $V$ has been considered the most important electrophysiological indicator for signaling auditory nerve damage by operative manipulations. ${ }^{[12,14,17]}$ Broggi $^{[6]}$ had suggested that the abolition of wave $V$ with preservation of wave I may be associated with good postoperative hearing function. Raudzens ${ }^{[11]}$ noticed that intraoperative BSAEPs were unchanged throughout surgery in 34 patients (74\%) and these individuals had no postoperative hearing deficits. Four patients had loss of all wave forms and this was correlated to deafness or hearing loss. They also felt that auditory morbidity had not declined with the increasing experience 
of the surgeon but it was seen in this series that this was not the case. Varying values of latency increase of wave V up to $1.5 \mathrm{~ms}$ have been to proposed to warn surgeons. Grundy ${ }^{[9]}$ used a delay of latency of peak wave $\mathrm{V}$ of $1.5 \mathrm{~ms}$ to warn the surgeon by modeling on the warnings given in their previous experience. Radtke ${ }^{[7]}$ chose latency changes equal to or greater than $1 \mathrm{~ms}$ to warn the surgeon. They commented that even though this value was chosen arbitrarily it was supported by the extremely low incidence of auditory complications seen in patients with shifts below this level. Hatayama ${ }^{[13]}$ analysed patients with latency of peak wave V more than $1 \mathrm{~ms}$ (38/350) and noted that $32 \%$ had postoperative hearing loss and felt that their results indicate that a latency change of more than $1 \mathrm{~ms}$ poses a substantial risk of postoperative hearing loss. Similarly, when the amplitude of wave Vwas decreased below 40, $61 \%$ of cases had statistically significant hearing loss. They commented that the amplitude of the components of the BSAEP was more valuable than latencies and suggested that a decrease in the amplitude of wave $\mathrm{V}$ by more than $40 \%$ seems to be criterion for predicting postoperative hearing loss. However Friedmann ${ }^{[8]}$ argued that false positive results will be frequent if latency criteria alone were used. They argued that as inter-peak latency was less affected by hypothermia, CSF drainage or depth of anesthesia, these are more sensitive to alterations secondary to surgical manipulations. They also suggested that simple prolongations of wave I, III and V latencies did not correlate with postoperative hearing deficit. They further suggested that notifying the surgeon regarding these prolongations may not be warranted. However, later studies have all felt the need for intraoperative $\mathrm{BSAEP}^{[4,7,10,13,14,17]}$ and warning the surgeon. Loiselle and Nuwer ${ }^{[18]}$ commented that over reliance upon arbitrary warning criteria invites inaccuracy, which leads to increased patient risk. However, the concept of watching the BAEP waveform deteriorate until just prior to the disappearance of wave $\mathrm{V}$ before warning the surgeon does not seem acceptable.

Most investigators ${ }^{[7,11,19,20]}$ have used empirically a $1.0 \mathrm{~ms}$ prolongation and greater than $50 \%$ decrease in amplitude of wave $\mathrm{V}$ as the criteria at which the surgeon has to be warned of impending damage.

Polo et $a l^{[14]}$ in a recent article on patients undergoing microvascular decompression for hemifacial spasm described as "critical warning" a delay of $1 \mathrm{~ms}$ in the latency of peak wave V. In this series it was seen that both amplitude as well as latency change was significant but the latency increase was more so. They also noted that $9.5 \%$ of patients had no subjective decrease in hearing but laboratory examination showed hearing loss exceeding $20 \mathrm{db}$.

In this series it was found that when the latency of wave V was more than $0.9 \mathrm{~ms}$ there was measurable hearing loss in $89 \%$ which was statistically significant. Regarding the amplitude it was seen that hearing loss was proportional to loss of amplitude above $50 \%$. However, further correlating increase in latency and decrease in amplitude of wave $\mathrm{V}$ with hearing loss was not possible. Four patients $(9 \%)$ in the Raudzens ${ }^{[11]}$ series developed an abrupt ipsilateral loss of all waveform components beyond Wave I and had postoperative evidence of a pronounced hearing loss in the affected ear. Radtke ${ }^{[7]}$ had three patients who had persistent loss of intraoperative BSAEP but only one of these patients had mild hearing loss suggestive of false positive result. Friedman ${ }^{[8]}$ also had one similar case. In the study by Polo ${ }^{[14]}$ there was a loss of hearing of $33.3 \%$ when wave $\mathrm{V}$ was abolished permanently. James $^{[21]}$ stated that commonly used warning values of a latency prolongation of $1.0 \mathrm{~ms}$ and amplitude decrement of $50 \%$ of wave $\mathrm{V}$ were not associated with hearing impairment. Using these warning values may needlessly prolong or alter the surgical procedure.

The most important finding in this study is the fact of the hearing loss was not appreciated by the patient. Most patients after MVD do not complain when asked about hearing loss especially when done at the bedside. This is because the patient may be using the better ear for hearing. As mentioned earlier some of the cases were tested clinically as well as by audiometry. Many authors ${ }^{[14,20]}$ have pointed out about hearing being preserved even though wave $\mathrm{V}$ was lost. In normal clinical practice it is accepted that loss of wave $\mathrm{V}$ is a pointer towards hearing loss. But in our series this was found to be not true.

In 11 patients (15\%) of there was an improvement in ipsilateral hearing postoperatively. This was also noted in $7 \%$ of patients in one study. ${ }^{[7]}$ There are several possible reasons for this:

a) The retest phenomenon (the patient learns how to do the test).

b) Postoperatively patients are pain-free and less anxious and therefore are able to concentrate better.

c) By 48 hours, medical therapy for trigeminal neuralgia (typically carbamezepine) is being reduced in most patients, which may improve hearing as these medications have significant cognitive side-effects.

The one self-criticism of this study is that postoperative hearing loss was assessed very early. But middle ear assessments were also done to check that the loss was not conductive in nature. Also, with the improvement in current anesthesia techniques, patients become conscious and alert immediately and are discharged home by 48 hours. These patients can undergo audiometry very well in the immediate postoperative period. Patients were followed up in three months time and if there was any concern about hearing, patient was referred to the audiology department. Eight patients had audiometry repeated at that time. However it was noticed that this was not at all different from the record done at the immediate postoperative period. So it was felt that there was no reason to repeat the audiogram in all cases.

This study came about as in our center it was assumed that after the wide use of BSAEP hearing loss was not an issue. But when the available information was viewed critically it was found that this was not the case. This paper highlights the problem of unilateral deafness after MVD not being observed by the patient. It also brings to focus the potential risk to patients having MVD on the side of their better hearing ear. It is suggested that patients who need to undergo MVD on the side of their better hearing ear need to be counseled that hearing could be compromised in that ear. 


\section{Conclusions}

A per-operative increase in latency greater than $0.9 \mathrm{~ms}$ or a decrease in amplitude of wave $\mathrm{V}$ below $50 \%$ indicates a risk to hearing and should be indicated to the surgeon. The majority of these impairments may not manifest clinically.

\section{References}

1. Barker FG $2^{\text {nd }}$, Jannetta PJ, Bissonette DJ, Larkins MV, Jho HD. The long-term outcome of microvascular decompression for trigeminal neuralgia. N Engl J Med 1996;334:1077-83.

2. Javadpour M, Eldridge PR, Varma TR, Miles .JB, Nurmikko T.J. Microvascular decompression for trigeminal neuralgia in patients over 70 years of age. Neurology $2003 ; 60: 520$.

3. Kolluri S, Heros RC. Microvascular Decompression for trigeminal neuralgia: A five year follow-up study. Surg Neurol 1984;22:235-40.

4. Nurmikko T.J, Eldridge PR. Trigeminal neuralgia - Pathophysiology, diagnosis and current treatment. Br J Anaesth 2001;87:117-32.

5. Zakrzewska JM, Patsalos PN. Long-term cohort study comparing medical (oxcarbazepine) and surgical management of intractable trigeminal neuralgia. Pain 2002;95:259-66

6. Broggi G, Scaioli V, Brock S, Dones I. Neurophysiological monitoring of cranial nerves during posterior fossa surgery. Acta Neurochir Suppl 1995;64:35-9.

7. Radtke AR, Erwin W, Wilkins RH. Intraoperative brainstem auditory evoked potentials: Significant decrease in postoperative morbidity. Neurology 1989;39:187-91.

8. Friedman WA, Kaplan BJ, Gravenstein D, Rhoton AL Jr. Intraoperative brainstem auditory evoked potentials during posterior fossa microvascular decompression. J Neurosurg 1985;62:552-7.

9. Grundy BL, Jannetta PJ, Procopio PT, Lina A, Boston JR, Doyle E. Intraoperative monitoring of brain-stem auditory evoked potentials. J Neurosurg 1982;57:674-81.

10. Moller AR, Moller MB. Does intraoperative monitoring of auditory evoked potentials reduce incidence of hearing loss as a complication of microvascular decompression of cranial nerves? Neurosurgery 1989;24:257-63.

11. Raudzens PA, Shetter AG. Intraoperative monitoring of brain stem auditory evoked potentials. J Neurosurg 1982;57:341-8.

12. Sindou M, Fobe JL, Ciriano D, Fischer C. Hearing prognosis and intra-operative guidance of brainstem auditory evoked potential in microvascular decompression. Laryngoscope 1992;102:678-82.

13. Hatayama T, Moller AR. Correlation between latency and amplitude of peak $\mathrm{V}$ in the brain stem auditory evoked potentials: Intra-operative recordings in microvascular decompression operations. Acta Neurochir 1998;140:681-7.

14. Polo G, Fischer C, Sindou MP, Marneffe V. Brainstem auditory evoked potential monitoring during microvascular decompression for hemifacial spasm: Intraoperative brainstem auditory evoked potential changes and warning values to prevent hearing loss- prospective study in a consecutive series of 84 patients. Neurosurgery 2004;54:97-106.

15. Moller AR, Jho HD, Yokota M, Jannetta PJ. Contribution from crossed and uncrossed brainstem structures to the brain-stem auditory evoked potentials: Study in humans. Laryngoscope 1995;105:596-605.

16. Rizvi SS, Goyal RN, Calder HB. Hearing preservation in microvascular decompression for trigeminal neuralgia. Laryngoscope 1999;109:591-4.

17. Meaney JF, Eldridge PR, Dunn LT, Nixon TE, Whitehouse GH, Miles JB. Demonstration of neurovascular compression in trigeminal neuralgia with magnetic resonance imaging. Comparison with surgical findings in 52 consecutive operative cases. J Neurosurg 1995;83:799-805.

18. Loiselle DL, Nuwer MR. When should we warn the surgeon? Diagnosis based warning criteria for BAEP monitoring. Neurology 2005;65:1522-3

19. Manninen PH, Patterson S, Lam AM, Gelb AW, Nantau WE. Evoked potential monitoring during posterior fossa aneurysm surgery: A comparison of two modalities. Can J Anaesth 1994;41:92-7.

20. Watanabe E, Schramm J, Strauss C, Fahlbusch R. Neurophysiologic monitoring in posterior fossa surgery. II. BAEP-waves I and V and preservation of hearing. Acta Neurochir (Wien) 1989;98:118-28

21. James ML, Husain AM. Brainstem auditory evoked potential monitoring. When is change in wave V significant? Neurology 2005;65:1551-5.

Accepted on 04-08-2006

\section{Author Help: Online Submission of the Manuscripts}

Articles can be submitted online from http://www.journalonweb.com. For online submission articles should be prepared in two files (first page file and article file). Images should be submitted separately.

1) First Page File:

Prepare the title page, covering letter, acknowledgement, etc., using a word processor program. All information which can reveal your identity should be here. Use text/rtf/doc/pdf files. Do not zip the files.

2) Article file:

The main text of the article, beginning from Abstract till References (including tables) should be in this file. Do not include any information (such as acknowledgement, your names in page headers, etc.) in this file. Use text/rtf/doc/pdf files. Do not zip the files. Limit the file size to $400 \mathrm{~kb}$. Do not incorporate images in the file. If file size is large, graphs can be submitted as images separately without incorporating them in the article file to reduce the size of the file.

3) Images:

Submit good quality colour images. Each image should be less than $\mathbf{1 0 0} \mathbf{~ k b}$ in size. Size of the image can be reduced by decreasing the actual height and width of the images (keep up to about 3 inches) or by reducing the quality of image. All image formats (jpeg, tiff, gif, bmp, png, eps, etc.) are acceptable; jpeg is most suitable. The image quality should be good enough to judge the scientific value of the image.

Always retain a good quality, high resolution image for print purpose. This high resolution image should be sent to the editorial office at the time of sending a revised article.

4) Legends:

Legends for the figures/images should be included at the end of the article file. 